\title{
A review of clinical efficacy, safety, new developments and adherence to allergen-specific immunotherapy in patients with allergic rhinitis caused by allergy to ragweed pollen (Ambrosia artemisiifolia)
}

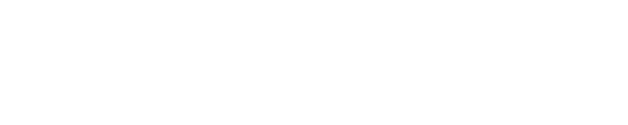

Mirjana Turkalj ${ }^{1,2}$

Ivana Banic'

Srdjan Ante Anzic'

'Children's Hospital Srebrnjak, Zagreb, ${ }^{2}$ Faculty of Medicine, JJ Strossmayer University of Osijek, Osijek, Croatia
Correspondence: Mirjana Turkalj Children's Hospital Srebrnjak, Srebrnjak 100, Zagreb 10000, Croatia Tel +385 I 639 I206

Email turkalj@bolnica-srebrnjak.hr

\begin{abstract}
Allergic rhinitis is a common health problem in both children and adults. The number of patients allergic to ragweed (Ambrosia artemisiifolia) is on the rise throughout Europe, having a significant negative impact on the patients' and their family's quality of life. Allergenspecific immunotherapy (AIT) has disease-modifying effects and can induce immune tolerance to allergens. Both subcutaneous immunotherapy and sublingual immunotherapy with ragweed extracts/preparations have clear positive clinical efficacy, especially over pharmacological treatment, even years after the treatment has ended. AIT also has very good safety profiles with extremely rare side effects, and the extracts/preparations used in AIT are commonly well tolerated by patients. However, patient adherence to treatment with AIT seems to be quite low, mostly due to the fact that treatment with AIT is relatively time-demanding and, moreover, due to patients not receiving adequate information and education about the treatment before it starts. AIT is undergoing innovations and improvements in clinical efficacy, safety and patient adherence, especially with new approaches using new adjuvants, recombinant or modified allergens, synthetic peptides, novel routes of administration (epidermal or intralymphatic), and new protocols, which might make AIT more acceptable for a wider range of patients and novel indications. Patient education and support (eg, recall systems) is one of the most important goals for AIT in the future, to further enhance treatment success.
\end{abstract}

Keywords: allergic rhinitis, allergy, ragweed, allergen-specific immunotherapy, Ambrosia artemisiifolia

\section{Introduction to Ambrosia artemisiifolia, ragweed pollen allergen extract in the management of allergic rhinitis}

Ambrosia artemisiifolia L. (Ambrosia elatior L., common ragweed) is a type of short ragweed of the Asteraceae (Compositae) family. Since its arrival to Europe, presumably by merchant ships from North America where it is indigenous, ragweed has been spreading invasively in many European countries. ${ }^{1,2}$ Figure 1 represents the ragweed plant at different vegetation states.

Type I hypersensitivity reactions (allergy) to ragweed pollen may manifest as symptoms of rhinitis, rhinoconjunctivitis, and allergic asthma. ${ }^{3}$ Since ragweed is spreading quickly in Europe, sensitization rates to Ambrosia are also increasing in all age groups, ranging from $15 \%$ to $\sim 80 \%$ throughout Central and Southeastern 


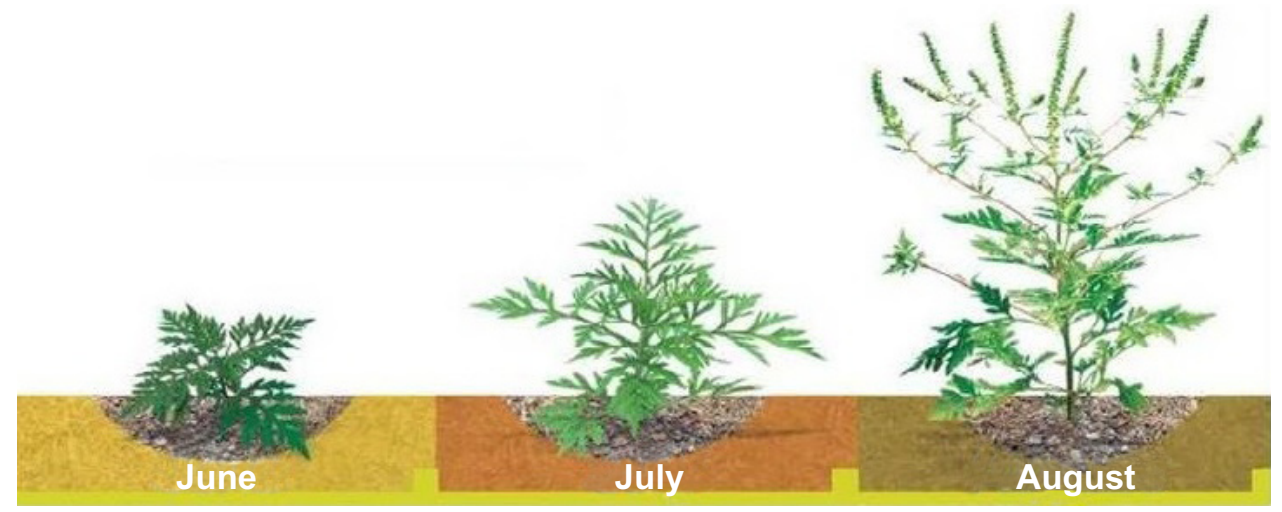

Figure I Ragweed (Ambrosia artemisiifolia) plant at different vegetation states.

Notes: June, young plant; July, growing plant, usually not yet pollinating; August, fully grown, pollinating plant.

Europe (Figure 2). Common ragweed is a highly allergenic plant species and one of the main causes of allergic rhinitis (AR) in North America and Europe, where it has been introduced only recently. ${ }^{4-13}$

According to the results of a recent study by the authors of this article involving $>4,000$ Croatian children aged 4-10 years, ragweed sensitization rates ranged from $1.5 \%$ to $15 \%$, primarily depending on ragweed pollen counts in the respective region (Mediterranean or continental), whereas sensitization rates to house dust mite were comparable in both regions (13\%; Turkalj, unpublished data, 2014). Ambrosia

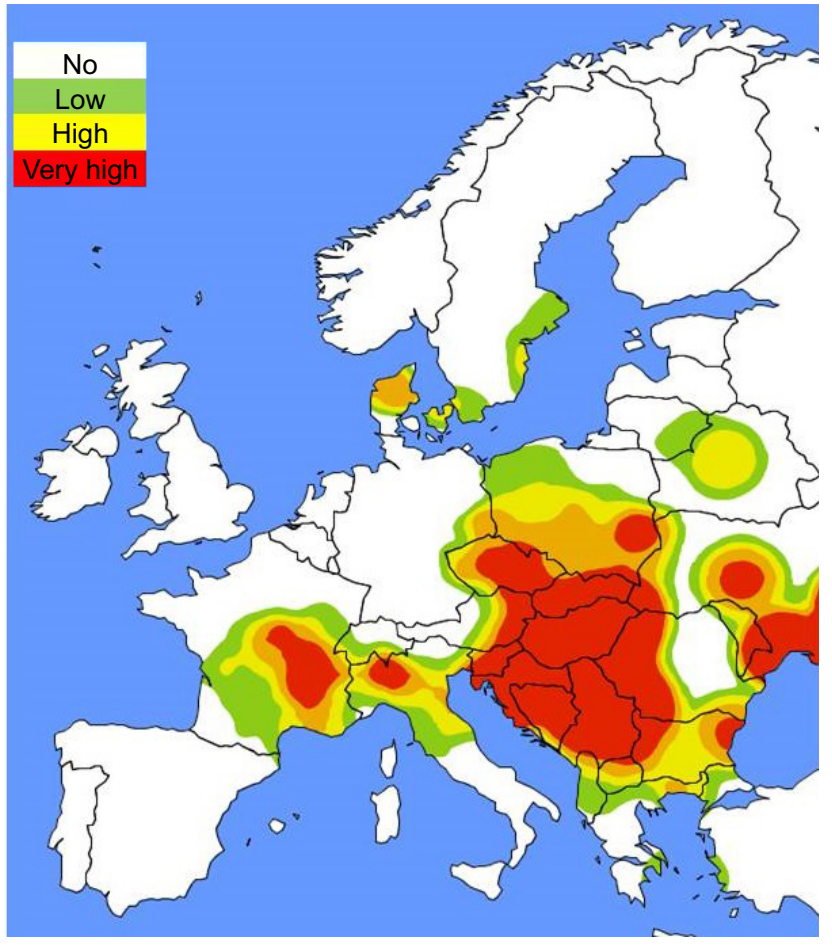

Figure 2 Ragweed pollen load map (according to average daily pollen counts) in Europe at the peak of pollination season (mid-September). ${ }^{90}$ pollination typically reaches peak levels in late summer (late August to mid-September) in Europe. The assessment and evaluation of exposure to ragweed pollen is of high importance for patients with allergy to ragweed. This is monitored using standardized aerobiological methodology (eg, pollen traps) on a daily basis. These data are used to foresee daily pollen exposure (pollen calendar), in order for patients to try to minimize the increased risk of exposure to allergen at specific days by undertaking preventive measures, such as staying indoors and using antihistamines. Allergic symptoms are usually monitored by pollen symptom diaries recording daily patient data on the frequency and severity of symptoms (upper or lower airways: rhinitis or asthma/wheezing, ocular, skin) and the use of medication. In the case of AR, the relationship between ragweed pollen concentrations and clinical symptoms exhibits a linear correlation. ${ }^{14}$

AR, caused by hypersensitivity to inhaled allergens including ragweed, is a common medical issue in all age groups (childhood, adolescence, adulthood), often having a negative impact on the overall quality of life of patients and their families. Moreover, AR and its associated comorbidities (such as asthma) generate substantial direct and indirect costs for European national budgets and significantly burden public health care systems. ${ }^{15}$ Treatment options for AR include measures of prevention, such as allergen avoidance (eg, during ragweed pollination season), anti-inflammatory symptomatic treatment (eg, intranasal corticosteroids and antihistamines), and allergen-specific immunotherapy (AIT). ${ }^{16}$

From a long-term, cost-benefit and cost-effectiveness point of view, AIT has clear advantages in the management of allergic rhinitis and asthma compared with pharmacotherapy, but it is also heavily dependent on the patient's compliance and adherence. Treatment of allergy (including AR) with AIT 
has disease-modifying effects, unlike other treatment options. In addition to reducing symptoms, AIT can change the course of the disease and induce allergen-specific immune tolerance. In AIT when allergen extracts (including ragweed allergen extracts) are administered, a number of immune responses are elicited, including the activation of specific blocking antibodies, tolerance-inducing cells, and mediators. This prevents further exacerbation of immune responses induced by allergens, blocking specific immune response to the allergen in question and attenuating the inflammatory response on the tissue level. ${ }^{17}$ AIT appears to have a clinical efficacy of up to 12 years and can prevent the development of asthma and hypersensitivity to novel allergens. ${ }^{18,19}$ Indications for AIT with ragweed allergen extracts/preparations include:

- Verification of immunoglobulin E (IgE)-mediated sensitization - not necessarily monosensitization (combining skin testing, eg, skin prick test [SPT] and in vitro diagnostics $^{20}$ - total and allergen-specific $\operatorname{IgE}$ in serum, especially elevated levels of specific IgE to ragweed major allergen Amb a 1, as well as novel in vitro methods, such as basophil activation test, with elevated levels of activated and degranulated basophils in response to ragweed allergens)-with a clear relationship to clinical history (symptoms of AR, rhinoconjunctivitis, and asthma).

- Availability of standardized or in-house high-quality allergen preparations.

- Proof of efficacy for the indication in question and respective age group (eg, in children).

- When allergen avoidance as a measure of prevention is impossible or inadequate.

- If the patient is older than 5 years (although AIT can be initiated in younger children).

In AIT, ragweed allergen extracts (modified or nonmodified allergens) are most commonly presented to the immune system via two routes of administration: subcutaneous immunotherapy (SCIT) or sublingual immunotherapy (SLIT). Both unmodified extracts with unaltered allergen (native) conformation and chemically modified extracts (allergoids) are acceptable for use in SCIT. In addition to aqueous extracts, depot extracts are also primarily used in Europe in SCIT. In depot extracts, non-modified allergens or allergoids are physically adsorbed to a carrier (eg, aluminum hydroxide, calcium phosphate, or L-tyrosine). Allergen extracts/preparations for SLIT are available with allergens in native conformation as well as chemically modified extracts, most commonly in the form of droplets (aqueous solution) or tablets.
Due to different and manufacturer-specific processing, allergen extracts differ in composition and allergenic potential (activity). Hence, they are only comparable to a certain extent, even if the same allergen sources are used. It is therefore recommended that standardized allergen extracts be used for AIT, as extracts may vary in biological activity. ${ }^{21}$ The total biological activity of allergen extracts is determined using in vitro methods such as enzyme-linked immunosorbent assay. Moreover, determining individual allergens (such as major allergen content) by the use of standardized, validated methodology is highly recommended by experts and international guidelines. ${ }^{22,23}$ Novel approaches to AIT include the use of new adjuvants or recombinant allergens and alternative routes of administration. ${ }^{24}$

\section{The mechanism of action of ragweed allergens in AIT}

More than 30 different allergenic proteins in A. artemisiifolia pollen (Figure 3A) have been purified and identified, many of which have multiple isoforms. ${ }^{25}$ The major allergen in common ragweed is Amb a 1, an acidic non-glycosylated $38 \mathrm{kDa}$ protein of the pectate lyase family, with 5 known isoallergen forms and sensitsation frequency greater than 95\% (Figure 3B).

A patient sensitized to ragweed allergens reacts upon repeated exposure to it, either via environmental exposure, by inhalation of ragweed pollen, or via specific immunotherapy (SIT). This elicits an inflammatory allergic response in the skin and mucosa. In SIT, allergen extracts diffuse into local tissue and are being taken up by antigen-presenting cells. ${ }^{26}$ The allergens are then soon found in local lymph nodes, where they arrive either unbound (via free diffusion) or are being taken up by dendritic cells (DCs) or B lymphocytes. ${ }^{27}$ Moreover, immune complexes involving allergens and $\operatorname{IgE}$ may form in the local tissue which can then activate mast and other cells or transport allergens to, eg, lymph nodes. Desensitization and immune tolerance to allergens by SIT are accomplished by the induction and activation of specific blocking antibodies, tolerance-inducing cells, and various mediator molecules. ${ }^{28-33}$ AIT also induces desensitization and tolerance to allergens by shifting the Th2 lymphocyte-mediated immune response toward a regulatory T-lymphocyte profile. Mechanisms underlying this process are not yet completely understood, but it is believed that DCs play an important role in regulating T-cell-related responses. Modifications in phenotype and occurrence of specific subsets of DCs in SIT indicate an altered capacity of DCs for the interaction with allergens. ${ }^{34}$ 

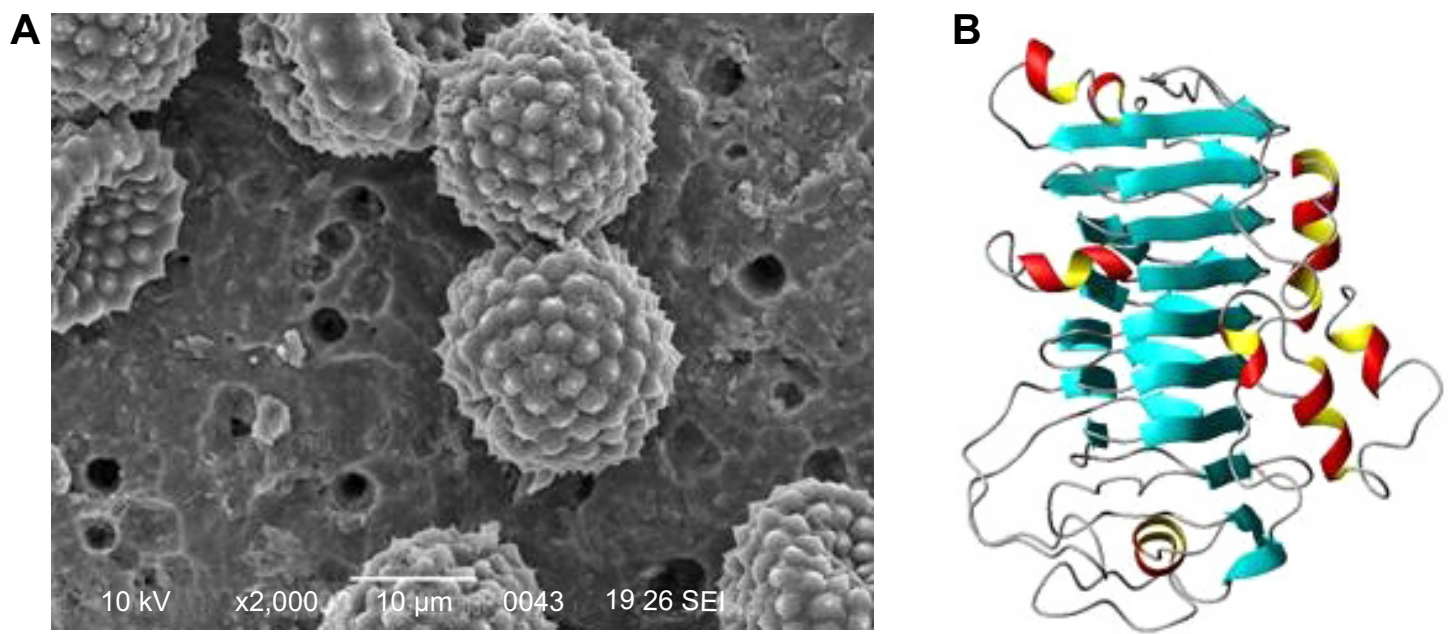

Figure 3 Ragweed (Ambrosia artemisiifolia) pollen.

Notes: (A) SEM image of ragweed pollen grains. Image courtesousy of Stephan Ango. (B) 3D model of the protein structure of ragweed major allergen Amb a I. Abbreviations: 3D, three-dimensional; SEM, scanning electron microscopy.

\section{Clinical efficacy in AIT with ragweed extracts}

The efficacy of AIT with ragweed allergens is evaluated in clinical studies ${ }^{35}$ using several scores as primary and secondary study end points. These include symptom scores (individual symptom scores and total symptom scores), scores involving data on medication use (medication scores), combined symptom and medication scores (CSMSs), scores involving data on health-related quality of life, etc. Because the development and improvements in AIT (new formulations, indications, protocols, etc) are not possible with conventional Phase I trials involving healthy subjects and because only allergic patients must be included in studies involving AIT, pharmacokinetic and pharmacodynamic studies are not possible because its products and/or metabolites cannot be detected in serum. Phase II trials for AIT are possible, but dose effect must be investigated and demonstrated in such trials. ${ }^{36}$ To assess whether immune tolerance has indeed been reached, it is also crucial to record other data, such as allergen exposure over time (ragweed pollen count during pollination season), safety data (adverse events, if any), and especially in vitro diagnostic data, such as serum levels of IgE (allergen-specific and total) and IgG (total IgG and subclass IgG4, in particular).

CSMSs have most frequently been used as primary end points in clinical trials involving AIT, but in many different variations. Due to a lack of validation of primary and secondary efficacy parameters, such study results are difficult to compare one with another. ${ }^{35,37}$ Recently, there have been efforts in harmonization and standardization of clinical study end points, ${ }^{38}$ such as the homogenous, standardized CSMS proposed by the European Academy of Allergy and Clinical Immunology (EAACI), ${ }^{39}$ as well as in the standardization of evaluation, presentation, and publication of clinical study results involving AIT. ${ }^{40}$ According to the World Allergy Organization's recommendations, the efficacy of AIT (its clinical effects, safety, and cost-effectiveness) should be at least comparable to that of pharmacologic treatment, with a threshold in efficacy of at least $20 \%$ higher than with placebo considered acceptable. ${ }^{41}$ It is noteworthy that, currently, the most effective pharmacotherapy has an efficacy of up to $19 \%$ above placebo, indicating clear advantages of AIT over pharmacologic treatment. ${ }^{42} \mathrm{~A}$ comparison of meta-analyses of double-blind placebo-controlled (DBPC) trials involving patients with AR on either SCIT to seasonal allergens (including ragweed) or pharmacological treatment demonstrated that, even in the first year of treatment, SCIT was successful in reducing allergic symptoms at least as good as (or better than) pharmacotherapy (symptomatic treatment). ${ }^{43}$ Numerous studies and meta-analyses clearly demonstrate the efficacy of AIT - both SCIT and SLIT for different age groups. A multicenter, parallel-group, open-controlled study involving patients with AR and/or asthma on SLIT with ragweed extract (in drop formulation) demonstrated a significant improvement in both objective (nasal provocation test and skin reactivity, SPT) and more subjective parameters (symptom score and medication score) ${ }^{44} \mathrm{~A}$ meta-analysis of 17 clinical DBPC randomized trials (DBPC RT) involving patients with AR on AIT for seasonal allergens (including ragweed) has confirmed significant benefits and advantages for both SCIT 
and SLIT in reducing symptom scores, medication scores and CSMS, as well as the overall quality-of-life scores over placebo in adults and children (but to a lesser extent). ${ }^{45}$

The efficacy of SLIT in managing AR, when compared with SCIT, still causes some controversy. A recent metaanalysis of SLIT with seasonal allergens (including ragweed) in patients with AR favored SLIT, with treatment durations ranging from $<6$ months to $>12$ months and major allergen content of $5-20 \mu \mathrm{g}$ as well as $>20 \mu \mathrm{g}$, demonstrating a significant decrease in symptom scores in both adults and children. ${ }^{46}$ A meta-analysis of studies involving SLIT with both seasonal and perennial allergens in pediatric patients with AR showed a significant reduction in symptoms and medication use scores, indicating that AIT treatment duration of $>18$ months and SLIT with pollen extracts were more beneficial than shorter durations of treatment and AIT with dust mite antigens. ${ }^{47}$ Benefits of AIT include long-lasting and preventive effects that can be observed even after the treatment has ended. An open, randomized study with children with AR (and with or without asthma) on SLIT demonstrated a significant decrease in the rate of new sensitization in children on SLIT versus controls. ${ }^{48}$ There are few controlled studies involving both SCIT and SLIT treatment groups for direct comparison. A comparison of the magnitude of effects in SLIT and SCIT demonstrated that the effects seen in SCIT may be more extensive than those in SLIT, although similar effects with SLIT (eg, in the decrease of serum sIgE levels) may be reached gradually and slower. ${ }^{49,50}$ Although large and structured clinical studies directly comparing the efficacy of SCIT and SLIT have not been performed, certain patients and physicians may favor
SLIT despite its slightly reduced efficacy due to significantly higher safety profile and convenience of administration (SLIT is generally administered at home by the patient himself/ herself or by parents/legal guardians in children). Several studies indicate that ragweed SLIT treatment regimes are clinically effective in different doses and generally safe and well tolerated (Table 1).

The introduction of AIT in the management of allergic asthma is generally made with greater caution, and AIT cannot be used as a substitute for common antiasthmatic treatment. AIT (SCIT or SLIT) can be recommended for intermittent or mild persistent asthma (Global Initiative for Asthma grades I and II). ${ }^{51}$ A meta-analysis of 88 randomized controlled studies involving patients with asthma on SCIT to different allergens demonstrated a significant reduction in both symptom and medication scores, as well as in bronchial hyperreactivity, but not an improvement in lung function (although a trend in improvement of lung function parameters was evident). ${ }^{52}$ Data on the efficacy of AIT to pollen allergens (including ragweed) in treating other indications such as oral allergy syndrome and atopic dermatitis are still insufficient, and further studies are needed. Despite that, certain randomized controlled trials exhibit positive effects (symptom score reduction, such as the scoring atopic dermatitis) and, moreover, prove that these conditions are not a contraindication for AIT in patients with airway allergy (eg, AR). ${ }^{53,54}$

An ideal case history (indication) for AIT with ragweed extracts would be a patient (adult or child) with AR caused by allergy to ragweed, preferably monosensitized, and not controlled well by common pharmacotherapy approaches. On the other hand, the majority of patients with AR are

Table I Administered doses and treatment schedules in SLIT formulations of Ambrosia in different studies in terms of clinical efficacy and safety

\begin{tabular}{|c|c|c|c|c|c|}
\hline Study & $\begin{array}{l}\text { Treatment } \\
\text { duration }\end{array}$ & $\begin{array}{l}\text { Treatment } \\
\text { dose }\end{array}$ & $\begin{array}{l}\text { Primary study } \\
\text { end point }\end{array}$ & Efficacy & Safety \\
\hline $\begin{array}{l}\text { Adults }(\mathrm{N}=96 \mathrm{I}) \\
\text { with ragweed- } \\
\text { induced } \mathrm{AR} / \mathrm{C} \text { with } \\
\text { or without asthma }{ }^{92}\end{array}$ & 12 months & $\begin{array}{l}6 \text { and } 12 \\
\text { Amb a } \mathrm{I}-\mathrm{U}\end{array}$ & $\begin{array}{l}\text { TCS based on } \\
\text { the sum DSS } \\
\text { and DMS }\end{array}$ & $\begin{array}{l}\text { TCS reduction with } 6 \text { and } 12 \text { Amb a } \\
I-U \text { was } 20 \% \text { and } 23 \% \text {, respectively } \\
(P<0.00 \mathrm{I}) \text {, compared to placebo }\end{array}$ & $\begin{array}{l}\text { Adverse events were generally mild } \\
\text { to moderate and transient, occurring } \\
\text { early in treatment; no systemic } \\
\text { allergic reaction/anaphylaxis recorded }\end{array}$ \\
\hline $\begin{array}{l}\text { Adults }(\mathrm{N}=784) \\
\text { with ragweed- } \\
\text { induced } A R / C^{93}\end{array}$ & 12 months & $\begin{array}{l}\mathrm{I} .5,6, \text { or } \mathrm{I} 2 \\
\text { Amb a I-U }\end{array}$ & TCS & $\begin{array}{l}\text { AIT of I.5, } 6 \text {, and I } 2 \text { Amb a I-U } \\
\text { reduced TCS by I } 2 \%(-0.88 ; P=0.09) \text {, } \\
\text { I8\% }(-I .28 ; P=0.0 \mathrm{I}) \text {, and } 27 \%(-I .92 ; \\
P<0.00 \mathrm{I}) \text {, respectively, compared to } \\
\text { placebo }\end{array}$ & $\begin{array}{l}\text { No systemic allergic reactions } \\
\text { recorded }\end{array}$ \\
\hline $\begin{array}{l}\text { Adults }(\mathrm{N}=565) \\
\text { with ragweed- } \\
\text { pollen-induced } \\
\text { AR/C }\end{array}$ & 12 months & $\begin{array}{l}6 \text { or } 12 \\
\text { Amb a } 1-U\end{array}$ & TCS & $\begin{array}{l}6 \text { and } 12 \text { Amb a I-U ragweed AIT doses } \\
\text { reduced TCS by } 21 \%(-I .76 \text { score }) \\
\text { and } 27 \%(-2.24 \text { score }) \text {, respectively, } \\
\text { compared to placebo }(P<0.05)\end{array}$ & $\begin{array}{l}\text { Adverse events were mild, oral } \\
\text { reactions; no systemic allergic } \\
\text { reactions recorded }\end{array}$ \\
\hline
\end{tabular}

Abbreviations: AIT, allergen-specific immunotherapy; AR/C, allergic rhinitis/rhinoconjunctivitis; DMS, daily medication score; DSS, daily symptom score; SLIT, sublingual immunotherapy; TCS, total combined score. 
polysensitized, and AIT has proven its efficacy in large, robust clinical trials in such patients, indicating that polysensitization neither is a contraindication for AIT nor does it affect its clinical efficacy (if polysensitization is defined correctly - not mistaken for polyallergy, for example). ${ }^{55,56}$ Finally, AIT is not necessarily suitable for all patients with AR (especially those with mild symptoms). Recent evidence from DBPC randomized clinical trials suggests that the more severe the disease, the greater the treatment effect. ${ }^{57}$

\section{Safety and tolerability profile of Ambrosia artemisiifolia extracts in AIT}

When administered in a proper manner and in correct dosage, notably in a medical institution, SCIT to ragweed is a very safe and well-tolerated treatment option. Local reactions at the site of injection include swelling, itching, redness, etc. They occur relatively frequently, but can be easily alleviated using local management measures (administering cooling packs or topical glucocorticoids at injection site or by using systemic antihistamines) ${ }^{58,59}$ In the case of more intense local reactions (redness and/or swelling of $>10 \mathrm{~cm}$ in diameter) at the site of injection, product information (manufacturer's instructions and allergen extract information - in case of in-house allergen preparations) should be carefully examined, primarily for information on dosage. This is also a requirement for further AIT planning (subsequent injections, schedule, and dosage correction, if needed). A US study involving patients on SCIT showed that such intense local reactions are not a predictor of an increased risk of systemic reactions. ${ }^{60}$ In the case of SCIT with products containing aluminum-based adjuvants, certain adverse effects, such as protein contact dermatitis, vasculitis type reactions, or granuloma, may occur due to reactions to foreign body, although this is very rare. Incorrect administration or previous/known aluminum contact allergy increases the risk of such reactions. If this occurs, switching to allergen extracts/preparations without aluminum adjuvants is highly recommended. ${ }^{61-63}$ These adverse reactions depend mostly on the quantity of aluminum adjuvants being used in allergen extracts, but, in general, the contribution of the use of aluminum adjuvants in AIT to the lifelong accumulation of aluminum in the human body is quite low. ${ }^{64}$

Systemic allergic reactions in SCIT vary from mild to severe skin or gastrointestinal symptoms (nausea, vomiting, diarrhea, generalized pruritus, urticaria, angioedema, etc), airway symptoms (upper airways [rhinitis, itchy throat, laryngeal/uvular/tongue edema], or lower airways [cough, stridor, shortness of breath], or life-threatening respiratory failure), cardiovascular symptoms (eg, hypotension), etc. ${ }^{65,66}$ Symptoms occurring within the first minute after SCIT injection may be a sign of severe anaphylaxis, and in such cases special precautions must be undertaken (the patients need to be monitored carefully and medication should be considered). This is why a minimum of 30-minute postinjection observation period by a health care professional (a doctor or a nurse) is required during SCIT. A retrospective analysis of a large cohort involving $>2,000$ patients receiving a large total number of injections $(\sim 200,000)$ during 10 years revealed that the total number of systemic reactions is extremely low (5.2\% and $0.06 \%$ of all injections) and that most of them occurred within the 30-minute postinjection observational period (at the physician's office or hospital), with no fatalities. ${ }^{67}$ An analysis of the American Academy of Allergy, Asthma and Immunology and EAACI involving 6.3 million SCIT injections per year demonstrated that the rate of systemic reactions was $\sim 0.1 \%$ of all injections, again with no fatalities. ${ }^{24}$ A study involving SCIT over a 12-year period of analysis estimated that the frequency of fatal reactions with clear causal relationship to SCIT was 1 in 2.5 million injections. ${ }^{68}$ The incidence of severe reactions to SCIT is estimated to be $0.002 \%-0.0076 \%$ of total injections for non-modified (native) allergen extracts and $0.0005 \%-0.01 \%$ for chemically modified allergen extracts. ${ }^{69-71}$ Common risk factors for systemic reactions during AIT and thus contraindications for the initiation of AIT with ragweed extracts include: current allergy symptoms and recent exposure to allergen, current infections, mast cell disease, hyperthyroidism, uncontrolled asthma, a high degree of sensitization, inadequate dose escalation, use of certain medication (eg, beta-blockers), physical exertion (intense physical activity and/or alcohol consumption just prior to the SCIT injection), poor administration techniques, allergen extract overdose, etc. If certain risk factors are taken into account, severe reactions to SCIT can sometimes be predicted and avoided with appropriate precaution steps and even prophylactic measures. It is possible to premedicate with antihistamines to reduce the frequency and severity of potential systemic reactions (especially when systemic reactions have previously occurred); however, this does not eliminate the possibility of systemic reactions. ${ }^{72,73}$

In the case of SLIT with ragweed extracts, when it is administered correctly to patients selected by specific indications and in proper dosage, SLIT is also a safe, effective, and well-tolerated choice of treatment in patients with AR caused by allergy to ragweed. ${ }^{74}$ Moreover, sublingual AIT is safe for home administration due to its excellent safety profile - perhaps the best of any treatment in allergic diseases. 
A recent review reported that 1 billion SLIT doses (including SLIT with ragweed extracts) were administered between 2000 and 2010 worldwide and that all eleven case reports of anaphylaxis (nonfatal) correspond to nonstandard practice: use of nonstandardized extracts, rush protocols, overdosing, and involving patients who had previously discontinued SCIT due to serious adverse events. ${ }^{75}$ Adverse events during SLIT are mostly dose dependent and, in the majority of cases, manifest as temporary local mucosal reactions such as oral symptoms and throat irritation (pruritus, swelling of mouth, tongue or lip, throat irritation, uvular edema, or gastrointestinal symptoms [abdominal pain, vomiting, diarrhea, etc]). ${ }^{76,77}$ These reactions usually occur during the initiation phase of SLIT, and they are mostly mild and temporary, subsiding in 1-3 weeks. ${ }^{78}$ Premedication with antihistamines is suitable in the case of local reactions during SLIT to reduce their extent, but again, it does not completely eliminate the possibility of recurrence of these reactions. In addition, SLIT is contraindicated in patients with severe asthma.

It is noteworthy that most adverse events during SLIT occur at home, where immediate and appropriate medical intervention is not possible. Although the risk of severe systemic adverse events is lower in SLIT than in SCIT, few cases of systemic reactions, including severe anaphylaxis, have been reported with SLIT in both droplet and tablet forms. However, these were all due to nonstandard treatment procedures: nonstandardized extracts, rush protocols, excessive allergen dose, patients who previously had severe systemic reactions during SCIT, etc. ${ }^{75}$ SLIT has also been reported to be safe for use in children younger than 5 years of age. ${ }^{79}$

Although the safety profile of SLIT is often considered to be better than the one in SCIT, health care professionals should be aware of the risks of AIT in general. Regardless of the route of allergen administration selected, patients should be educated on expected (and usually harmless) side effects versus true severe systemic reactions. SCIT is routinely administered in a medical institution following careful periods of monitoring. It is also highly recommended that SLIT should also be initiated at a medical institution by health care professionals and if all goes well, SLIT doses are safe to be administered at home by the patient himself/ herself or by parents/legal guardians in children. Although it is very rare, the risk of anaphylaxis is always present with AIT; therefore, patients on both SCIT and SLIT should carry an emergency epinephrine injector at all times and be fully educated on its appropriate use.

Finally, before the initiation of AIT to ragweed, a list of additional medications (eg, beta-blockers, angiotensin-converting enzyme $[\mathrm{ACE}]$ inhibitors, and antidepressants) should be obtained, as well as any known or suspected allergies to medications or adverse reactions to aspirin. Concomitant use of beta-blockers as well as ACE inhibitors and allergen immunotherapy should be carefully considered from an individualized risk/benefit standpoint and incorporate the patient's preferences in the medical decision-making process.

\section{Patient-focused perspectives in AlT with ragweed extracts}

The success and clinical efficacy of AIT largely depends on its duration and appropriateness of use in accordance with the physician's recommendations, especially for home administration of SLIT where health care professionals have no control of the treatment being performed properly. Moreover, treatment success with AIT is greatly influenced by patient adherence to it. Thoroughly informing the patient about the treatment, ie, how it works, when and how it should be administered and emphasizing the important role of the patient himself/herself in the process of treatment significantly improves the clinical efficacy of AIT ${ }^{80}$ Severe reactions during AIT are commonly due to patient's insufficient compliance, eg, the patient does not stay under surveillance at the medical institution long enough after the injection, inappropriate physical exertion (rigorous exercise, sauna, alcohol consumption) is made just prior to the injection, the patient increases the duration of time periods between injections, etc. At this point, the physician should carefully consider about continuation or discontinuation of SCIT. Particularly in the early phases of treatment with SLIT to ragweed, mild local reactions (swelling, itchiness) may cause self-discontinuation of treatment by the patient. It is thus very important that the patient is thoroughly informed before the treatment with AIT starts, that he/she is warned about the possibility of these reactions, instructed what to do if these reactions occur (ie, how to monitor and manage them or consider notifying a health care professional), and informed that these reactions are temporary in the vast majority of cases. A lack of patient compliance, newly arising contraindications, persisting unacceptable local adverse events, severe reactions, and a lack of clinically measurable response after 2 years of treatment with SLIT are objective indications for early discontinuation of treatment. ${ }^{72}$

According to some data, reasons for premature discontinuation of AIT may be largely based on informing the patient inadequately, especially on the way the treatment is carried out, for how long, etc. With clear advantages of AIT in clinical efficacy over pharmacological treatment and 
long-term alleviation of troublesome allergic symptoms and, moreover, with the advantage of SLIT being applicable in the comfort of one's home, it would initially seem that the patients' satisfaction and quality of life are excellent, especially when compared to using multiple forms of pharmacotherapy. However, quite low adherence rates for both SCIT and SLIT suggest otherwise. A study on adherence and the overall quality of life during SCIT and SLIT reported that heavy time demands of the treatment was considered a problem by $\sim 70 \%$ of patients and $>60 \%$ of them report adverse events as a major problem during AIT. Approximately $60 \%$ of patients claim they experienced no or inadequate reduction of symptoms and more than half of them were unsatisfied because they had not received adequate information about the treatment and were not informed about everything that their condition and treatment with AIT imply. ${ }^{81}$ Most common reasons for failure in compliance and adherence in AIT include:

- Patient-related reasons: the patient is not informed adequately or not motivated or has no adequate understanding of clinical implications in allergy or primary and secondary preventive effects of AIT.

- Treatment-related reasons: occurrence of side effects, a reduction in symptoms score and medication use is not observed, and inadequate patient selection (incorrect indications).

- Clinical practice-related reasons: heavy time demands for the patients (especially with SCIT), the treatment is not integrated into the patient's daily life, and no recall system or patient counseling (probably due to limited financial resources).

Low treatment adherence seriously affects treatment success with AIT. A study by the German statutory health care insurance demonstrated a clear decrease in the persistence rates of SCIT over the years: only $24 \%$ of the patients continued their treatment into the third year. ${ }^{82}$ Another analysis of German prescription data on SCIT and SLIT products exhibited an unsatisfactory adherence rate and persistence rates into the third year of treatment in $34 \%-51 \%$ of adult patients and of $44.1 \%$ in children and adolescents (aged $4-18$ years). ${ }^{83}$ When it comes to patient adherence to AIT with ragweed extracts, one might think that adherence is better for SCIT than SLIT as SCIT is usually administered by a health care professional. However, just how much this affects SCIT having a better adherence profile over SLIT is controversial due to a general lack of adequate studies. Several studies indicate that there are no differences in compliance rates between SCIT and SLIT, varying between $75 \%$ and $90 \%$, although one study suggests that 3-year persistence rates are slightly better in SCIT users than in SLIT users (23\% vs 7\%, respectively). ${ }^{84}$ However, all these data originate from clinical trials and can hardly reflect treatment adherence in real-life conditions. ${ }^{78}$ Improvements in adherence to AIT represent one of the most important goals for AIT in the future, to maximize treatment success.

\section{Recommendations for the future}

Despite the fact that AIT has been successfully used to treat allergic diseases, including AR, for $>100$ years, a number of important questions remain to be addressed primarily with large, randomized, multicenter trials and, more importantly, with improvements in treatment organization and patient adherence.

Future requirements for AIT with ragweed extracts include:

1. Standardization and validation of clinical end points in trials involving AIT (eg, CSMS). This will ensure better comparability of clinical results involving different allergen preparations and different age groups and clearly define the period during which data on clinical symptoms will be recorded.

2. Further research on immune mechanisms underlying AIT and development of immune tolerance and desensitization.

3. Clear definition of indications for AIT, including those in polysensitized patients, and definition of preventive and long-term clinical effects in all age groups.

4. More detailed recording and analysis of data regarding safety.

5. Direct comparison of different allergen preparations (unmodified vs modified), treatment regimes, and modes of administration (SCIT vs SLIT) in terms of clinical efficacy, safety, adherence to treatment, etc.

6. Development of new or improved diagnostic methods/ biomarkers to optimize patient selection for AIT and phenotyping according to specific indication.

7. Standardization and validation of methods for determining (major) allergen content in different preparations.

8. Identification and validation of biomarkers which will serve as prediction factors for treatment success in AIT.

9. Development and validation of new approaches in AIT: confirmation of clinical efficacy and safety of AIT using new adjuvants, synthetically produced peptides, recombinant or modified allergens, as well as new modes of administration.

10. Development of programs to further increase patient adherence: education, recall systems, etc. 
11. Cost-effectiveness studies involving AIT ( $>3$ years in duration).

By using novel or optimized adjuvants, stronger stimulation of the immune system could be achieved at unchanged doses or with higher doses, but without the increased risk for adverse events. ${ }^{85,86} \mathrm{With}$ recombinant allergens, allergen preparations can be produced more precisely in terms of concentrations and quality, with standardized methods, and moreover modifying such allergens could enable the development of novel products with optimized efficacy and fewer side effects. ${ }^{87}$ Furthermore, with the use of recombinant allergens, AIT may be used in new indications such as food allergy. By using alternative administration sites or modes, such as epidermal immunotherapy or intralymphatic immunotherapy, desired or better immune responses could be achieved in more convenient forms (patches) or with fewer injections. ${ }^{88}$ The use of combination treatment with humanized anti-IgE antibody could enable AIT to be introduced in patients with conditions currently considered to be contraindications for AIT (such as moderate or severe bronchial asthma) due to serious side effects. ${ }^{89}$

\section{Conclusion}

AIT with ragweed extracts is a clinically highly effective, safe and well-tolerated treatment option in the management of allergic disease (such as AR). It is currently going through major improvements and innovations, with many of them already being tested in clinical settings or even awaiting approval for market use. This will certainly enhance the disease-modifying effects of AIT, make it acceptable to a wider range of patients (all age groups, additional indications), which will motivate the patients to adhere better to AIT, and thus perhaps lead to AIT becoming the primary treatment option in the management of AR caused by type I hypersensitivity reactions to allergens, including ragweed.

\section{Disclosure}

The authors report no conflicts of interest in this work.

\section{References}

1. Cvitanovic S, Znaor L, Kanceljak-Macan B, Macan J, Gudelj I, Grbic D. Allergic rhinitis and asthma in Southern Croatia: impact of sensitisation to Ambrosia elatior. Croat Med J. 2007;48(1):68-75.

2. Barnes C, Pacheco F, Landuyt J, Hu F, Portnoy J. Hourly variation of airborne ragweed pollen in Kansas City. Ann Allergy Asthma Immunol. 2001;86(2):166-171.

3. Taramarcaz P, Moetteli L, Eigenmann P. Prevalence of ragweed allergy in rural Geneva - a pilot study. Swiss Med Wkly. 2015;145:w14198.

4. Burbach GJ, Heinzerling LM, Röhnelt C, Bergmann KC, Behrendt H, Zuberbier T. Ragweed sensitization in Europe - GA2LEN study suggests increasing prevalence. Allergy. 2009;64(4):664-665.
5. Mezei G, Jarai-Komoldi M, Medzihradsky Z, Cserhati E. Seasonal allergenic rhinitis and pollen count (a 5-year survey in Budapest). Orv Hetil. 1995;136(2):1721-1724.

6. de Weger LA, Pashley CH, Šikoparija B, et al. The long distance transport of airborne Ambrosia pollen to the UK and the Netherlands from Central and south Europe. Int J Biometeorol. Epub 2016 Apr 27.

7. Della Torre F, Sala S, Sciancalepore L, Cassani L, Piazza G. Ragweed and allergy: epidemiology. Allergy. 1996;51:123.

8. Peternel R, Music Milanovic S, Srnec L. Airborne ragweed (Ambrosia artemisiifolia L.) pollen content in the city of Zagreb and implications on pollen allergy. Ann Agric Environ Med. 2008;15(1):125-130.

9. Laaidi M, Laaidi K, Besancenot J, Thibaudon M. Ragweed in France: an invasive plant and its allergenic pollen. Ann Allergy Asthma Immunol. 2003;91(2):195-201.

10. Tossi A, Wütrich B, Bonini M, Pietragalla-Köhler B. Time lag between Ambrosia sensitisation and Ambrosia allergy: a 20-year study (19892008) in Legnano, northern Italy. Swiss Med Wkly. 2011;141:w13253.

11. Jäger S. Ragweed (Ambrosia) sensitisation rates correlate with the amount of inhaled airborne pollen. A 14-year study in Vienna, Austria. Aerobiologia. 2000;16:149-153.

12. Rybnicek O, Jäger S. Ambrosia (ragweed) in Europe. Allergy Clin Immunol Int. 2001;13:60-66.

13. Taramarcaz P, Lambelet B, Clot B, Keimer C, Hauser C. Ragweed (Ambrosia) progression and its health risks: will Switzerland resist this invasion? Swiss Med Wkly. 2005;135(37-38):538-548.

14. Caillaud D, Thibaudon M, Martin S, et al. Short-term effects of airborne ragweed pollen on clinical symptoms of hay fever in a panel of 30 patients. J Investig Allergol Clin Immunol. 2014;24(4): 249-256.

15. Roberts G, Xatzipsalti M, Borrego LM, et al. Paediatric rhinitis: position paper of the European Academy of Allergy and Clinical Immunology. Allergy. 2013;68(9):1102-1116.

16. Santos A, Borrego L, Rotiroti G, Scadding G, Roberts G. The need for patient-focused therapy for children and teenagers with allergic rhinitis: a case-based review of current European practice. Clin Transl Allergy. 2015;5(1):2.

17. Pfaar O, Bachert C, Bufe A, et al. Guideline on allergen-specific immunotherapy in IgE-mediated allergic diseases. Allergo J Int. 2014; 23(8):282-319.

18. Eng PA, Borer-Reinhold M, Heijnen IA, Gnehm HP. Twelve-year follow-up after discontinuation of pre-seasonal grass pollen immunotherapy in childhood. Allergy. 2006;61(2):198-201.

19. Jacobsen L, Niggemann B, Dreborg S, et al. Specific immunotherapy has long-term preventive effect of seasonal and perennial asthma: 10-year follow-up on the PAT study. Allergy. 2007;62(8):943-948.

20. Spehar M, Dodig S, Hrga I, Simic D, Turkalj M, Venus M. Concentration of $\operatorname{IgE}$ in children during ragweed pollination season. Aerobiologia (Bologna). 2010;1:29-34.

21. Li JT, Lockey RF, Bernstein I, Portnoy JM, Nicklas RA. Allergen immunotherapy: a practice parameter. Ann Allergy Asthma Immunol. 2003;90(suppl 1):1-40.

22. EMEA/CHMP/BWP, European Medicines Agency, Committee for Medicinal Products for Human Use. Guideline on Allergen Products: Production and Quality Issues. London: European Medicines Agency; Committee for medicinal products for Human Use; 2008. EMEA/ CHMP/BWP/304831/2007.

23. van Ree R, Chapman MD, Ferreira F, et al. The CREATE project: development of certified reference materials for allergenic products and validation of methods for their quantification. Allergy. 2008;63(3): 310-326.

24. Burks AW, Calderon MA, Casale T, et al. Update on allergy immunotherapy: American Academy of Allergy, Asthma \& Immunology/ European Academy of Allergy and Clinical Immunology/ PRACTALL consensus report. J Allergy Clin Immunol. 2013;131(5): 1288.7e3-1296.7e3.

25. El Kelish A, Zhao F, Heller W, et al. Ragweed (Ambrosia artemisiifolia) pollen allergenicity: superSAGE transcriptomic analysis upon elevated CO2 and drought stress. BMC Plant Biol. 2014;14:176. 
26. Bagnasco M, Altrinetti V, Pesce G, et al. Pharmacokinetics of Der p 2 allergen and derived monomeric allergoid in allergic volunteers. Int Arch Allergy Immunol. 2005;138(3):197-202.

27. Allam J, Würtzen $P$, Reinartz M, et al. Phl p 5 resorption in human oral mucosa leads to dose-dependent and time-dependent allergen binding by oral mucosal Langerhans cells, attenuates their maturation, and enhances their migratory and TGF-beta1 and IL-10-producing properties. J Allergy Clin Immunol. 2010;126(3):638.e1-645.e1.

28. Akdis M, Akdis CA. Mechanisms of allergen-specific immunotherapy. J Allergy Clin Immunol. 2007;119(4):780-791.

29. Nouri-Aria KT, Wachholz PA, Francis JN, et al. Grass pollen immunotherapy induces mucosal and peripheral IL-10 responses and blocking IgG activity. J Immunol. 2004;172(5):3252-3259.

30. Akdis CA, Akdis M. Mechanisms of immune tolerance to allergens: role of IL-10 and Tregs. J Clin Invest. 2014;124(11):4678-4680.

31. Takhar P, Smurthwaite L, Coker HA, et al. Allergen drives class switching to IgE in the nasal mucosa in allergic rhinitis. J Immunol. 2005; 174(8):5024-5032.

32. Reisinger J, Horak F, Pauli G, et al. Allergen-specific nasal IgG antibodies induced by vaccination with genetically modified allergens are associated with reduced nasal allergen sensitivity. J Allergy Clin Immunol. 2005;116(2):347-354.

33. Akdis M, Verhagen J, Taylor A, et al. Immune responses in healthy and allergic individuals are characterized by a fine balance between allergen-specific T regulatory 1 and T helper 2 cells. J Exp Med. 2004; 199(11):1567-1575.

34. Lundberg K, Rydnert F, Broos S, Andersson M, Greiff L, Lindstedt M. Allergen-specific immunotherapy alters the frequency, as well as the FcR and CLR expression profiles of human dendritic cell subsets. PLoS One. 2016;11(2):e0148838.

35. Pfaar O, Kleine-Tebbe J, Hörmann K, Klimek L. Allergen-specific immunotherapy: which outcome measures are useful in monitoring clinical trials? Immunol Allergy Clin North Am. 2011;31(2):289-309.

36. Demoly P, Calderon MA. Dosing and efficacy in specific immunotherapy. Allergy. 2011;66(suppl s95):38-40.

37. Calderon MA, Eichel A, Makatsori M, Pfaar O. Comparability of subcutaneous and sublingual immunotherapy outcomes in allergic rhinitis clinical trials. Curr Opin Allergy Clin Immunol. 2012;12(3):249-256.

38. EMA/CHMP. Guideline on the Clinical Development of Products for Specific Immunotherapy for the Treatment of Allergic Diseases. London: European Medicines Agency Committee for Medicinal Products for Human Use; 2008. CHMP/EWP/18504/2006.

39. Pfaar O, Demoly P, Gerth van Wijk R, et al. Recommendations for the standardization of clinical outcomes used in allergen immunotherapy trials for allergic rhinoconjunctivitis: an EAACI Position Paper. Allergy. 2014;69(7):854-867.

40. Bousquet PJ, Brozek J, Bachert C, et al. The CONSORT statement checklist in allergen-specific immunotherapy: a GA2LEN paper. Allergy. 2009;64(12):1737-1745.

41. Canonica GW, Baena-Cagnani CE, Bousquet J, et al. Recommendations for standardization of clinical trials with Allergen Specific Immunotherapy for respiratory allergy. A statement of a World Allergy Organization (WAO) taskforce. Allergy. 2007;62(3):317-324.

42. Carr W, Bernstein J, Lieberman P, et al. A novel intranasal therapy of azelastine with fluticasone for the treatment of allergic rhinitis. J Allergy Clin Immunol. 2012;129(5):1282-1289.

43. Matricardi PM, Kuna P, Panetta V, Wahn U, Narkus A. Subcutaneous immunotherapy and pharmacotherapy in seasonal allergic rhinitis: a comparison based on meta-analyses. J Allergy Clin Immunol. 2011;128(4):791-799.

44. Valle C, Bazzi S, Berra D, Sillano V, Puccinelli P, Parmiani S. Effects of sublingual immunotherapy in patients sensitised to Ambrosia. An open controlled study. Allergol et Immunopathol. 2000;28(6):311-317.

45. Dretzke J, Meadows A, Novielli N, Huissoon A, Fry-Smith A, Meads C. Subcutaneous and sublingual immunotherapy for seasonal allergic rhinitis: a systematic review and indirect comparison. J Allergy Clin Immunol. 2013;131(5):1361-1366.
46. Radulovic S, Calderon MA, Wilson D, Durham S. Sublingual immunotherapy for allergic rhinitis. Cochrane Database Syst Rev. 2010;8(12): CD002893.

47. Penagos M, Compalati E, Tarantini F, et al. Efficacy of sublingual immunotherapy in the treatment of allergic rhinitis in pediatric patients 3 to 18 years of age: a meta-analysis of randomized, placebo-controlled, doubleblind trials. Ann Allergy Asthma Immunol. 2006;97(2):141-148.

48. Marogna M, Tomassetti D, Bernasconi A, et al. Preventive effects of sublingual immunotherapy in childhood: an open randomized controlled study. Ann Allergy Asthma Immunol. 2008;101(2):206-211.

49. Cox L. Sublingual immunotherapy and allergic rhinitis. Curr Allergy Asthma Rep. 2008;8(2):102-110.

50. Aasbjerg K, Backer V, Lund G, et al. Immunological comparison of allergen immunotherapy tablet treatment and subcutaneous immunotherapy against grass allergy. Clin Exp Allergy. 2014;44(3): 417-428.

51. GINA [homepage on the Internet]. Global Strategy for Asthma Management and Prevention: Global Initiative for Asthma; 2006. Available from: www.ginasthma.org. Accessed May 14, 2013.

52. Abramson MJ, Puy RM, Weiner JM. Injection allergen immunotherapy for asthma. Cochrane Database Syst Rev. 2010;4(8):CD001186.

53. Mauro M, Russello M, Incorvaia C, et al. Birch-apple syndrome treated with birch pollen immunotherapy. Int Arch Allergy Immunol. 2011; 156(4):416-422.

54. Bae JM, Choi YY, Park CO, Chung KY, Lee KH. Efficacy of allergenspecific immunotherapy for atopic dermatitis: a systematic review and meta-analysis of randomized controlled trials. J Allergy Clin Immunol. 2013;132(1):110-117.

55. Calderon MA, Frankland WA, Demoly P. Allergen immunotherapy and allergic rhinitis: false beliefs. BMC Med. 2013;11:255

56. Migueres M, Davila I, Frati F, et al. Types of sensitisation to aeroallergens: definitions, prevalences and impact on the diagnosis and treatment of allergic respiratory disease. Clin Transl Allergy. 2014; $4: 16$.

57. Durham SR, Birk AO, Andersen JS. Days with severe symptoms: an additional efficacy endpoint in immunotherapy trials. Allergy. 2011; 66(1):120-123.

58. Cox L, Calderon M, Pfaar O. Subcutaneous allergen immunotherapy, safety and cost-effectiveness of current and novel formulations. Immunotherapy. 2012;4(6):601-616.

59. Malling HJ. Minimising the risks of allergen-specific injection immunotherapy. Drug Saf. 2000;23(4):323-332.

60. Kelso JM. The rate of systemic reactions to immunotherapy injections is the same whether or not the dose is reduced after a local reaction. Ann Allergy Asthma Immunol. 2004;92(2):225-227.

61. Vogelbruch M, Nuss B, Körner M, Kapp A, Kiehl P, Bohm W. Aluminium-induced granulomas after inaccurate intradermal hyposensitisation injections of aluminium-adsorbed depot preparations. Allergy. 2000;55(9):883-887.

62. Netterlid E, Hindsén M, Björk J, et al. There is an association between contact allergy to aluminium and persistent subcutaneous nodules in children undergoing hyposensitisation therapy. Contact Dermatitis. 2009;60(1):41-49.

63. Frost L, Johansen P, Pedersen S, Veien N, Ostergaard PA, Nielsen MH. Persistent subcutaneous nodules in children hyposensitized with aluminium-containing allergen extracts. Allergy. 1985;40(5): 368-372.

64. Lopez S, Pelaez A, Navarro LA, Montesinos E, Morales C, Carda C. Aluminium allergy in patients hyposensitized with aluminium-precipitated antigen extracts. Contact Dermatitis. 1994;31(1):37-40.

65. Cox L, Larenas-Linnemann D, Lockey RF, Passalacqua G. Speaking the same language: the World Allergy Organization subcutaneous immunotherapy systemic reaction grading system. J Allergy Clin Immunol. 2010;125(3):569-574.

66. Passalacqua G, Baena-Cagnani CE, Bousquet J, et al. Grading local side effects of sublingual immunotherapy for respiratory allergy: speaking the same language. J Allergy Clin Immunol. 2013;132(1):93-98. 
67. Ragusa FV, Passalacqua G, Gambardella R, et al. Nonfatal systemic reactions to subcutaneous immunotherapy: a 10-year experience. J Investig Allergol Clin Immunol. 1997;7(3):151-154.

68. Bernstein DI, Wanner M, Borish L, Liss GM; Immunotherapy Committee, American Academy of Allergy, Asthma and Immunology. Twelveyear survey of fatal reactions to allergen injections and skin testing: 1990-2001. J Allergy Clin Immunol. 2004;113(6):1129-1136.

69. Caminati M, Dama AR, Djuric I, et al. Incidence and risk factors for subcutaneous immunotherapy anaphylaxis: the optimization of safety. Expert Rev Clin Immunol. 2015;11(2):233-245.

70. Makatsori M, Calderon MA. Anaphylaxis: still a ghost behind allergen immunotherapy. Curr Opin Allergy Clin Immunol. 2014;14(4):316-322.

71. Lüderitz-Püchel U, Keller-Stanislawski B, Haustein D. Risk reevaluation of diagnostic and therapeutic allergen extracts. An analysis of adverse drug reactions from 1991 to 2000. Bundesgesundheitsbl Gesundheitsforsch Gesundheitsschutz. 2001;44:709-718.

72. Alvarez-Cuesta E, Bousquet J, Canonica GW, et al. Standards for practical allergen-specific immunotherapy. Allergy. 2006;82(suppl):1-20

73. Nielsen L, Johnsen CR, Mosbech H, Poulsen LK, Malling HJ. Antihistamine premedication in specific cluster immunotherapy: a double-blind, placebo-controlled study. J Allergy Clin Immunol. 1996;97(6):1207-1213.

74. Li JT, Bernstein DI, Calderon MA, et al. Sublingual grass and ragweed immunotherapy: clinical considerations-a PRACTALL consensus report. J Allergy Clin Immunol. 2016;137(2):369-376.

75. Calderón MA, Simons FE, Malling HJ, Lockey RF, Moingeon P, Demoly P. Sublingual allergen immunotherapy: mode of action and its relationship with the safety profile. Allergy. 2012;67(3):302-311.

76. Cox LS, Larenas-Linnemann D, Nolte H, Weldon D, Finegold I, Nelson HS. Sublingual immunotherapy: a comprehensive review. J Allergy Clin Immunol. 2006;117(5):1021-1035.

77. Passalacqua G, Garelli V, Sclifò F, Canonica GW. Sublingual immunotherapy for allergic rhinitis and conjunctivitis. Immunotherapy. 2013; 5(3):257-264.

78. Canonica GW, Cox L, Pawankar R, et al. Sublingual immunotherapy: World Allergy Organization position paper 2013 update. World Allergy Organ J. 2014;7(1):6.

79. Fiocchi A, Pajno G, La Grutta S, et al. Safety of sublingual-swallow immunotherapy in children aged 3 to 7 years. Ann Allergy Asthma Immunol. 2005;95(3):254-258.

80. Baiardini I, Braido F, Bonini M, Compalati E, Canonica GW. Why do doctors and patients not follow guidelines? Curr Opin Allergy Clin Immunol. 2009;9(3):228-233.

81. Sondermann N, Shah-Hosseini K, Henkel K, Schwalfenberg A, Mösges R. Factors of success for adherence in hyposensitisation. Allergologie. 2011;34:441-446.
82. Claes C, Mittendorf T, Graf von der Schulenburg JM. Persistence and frequency of prescriptions of subcutaneous allergen-specific immunotherapy (SCIT) prescribed within the German statutory health insurance. Med Klin. 2009;104(7):536-542.

83. Eberle P, Schreder H, Shah-Hosseini K, Mösges R. Medication persistence in children and young people on long-term grass pollen specific immunotherapy - measured by prescription renewal rates. Allergologie. 2013;36:9-18.

84. Kiel MA, Röder E, Gerth van Wijk R, Al MJ, Hop WC, Rutten-van Mölken MP. Real-life compliance and persistence among users of subcutaneous and sublingual allergen immunotherapy. J Allergy Clin Immunol. 2013;132(2):353-362.

85. Reeve L, Baldrick P, Hewings S, Skinner M. A battery of genotoxicity studies with an allergy vaccine adjuvanted with monophosphoryl lipid A (MPL®) for the treatment of grass pollen allergy. J Appl Toxicol. 2012; 32(8):608-616.

86. Pfaar O, Cazan D, Klimek L, Larenas-Linnemann D, Calderon MA. Adjuvants for immunotherapy. Curr Opin Allergy Clin Immunol. 2012; 12(6):648-657.

87. Jutel M, Solarewicz-Madejek K, Smolinska S. Recombinant allergens: the present and the future. Hum Vaccin Immunother. 2012;8(10): 1534-1543.

88. Johansen P, von Moos S, Mohanan D, Kündig TM, Senti G. New routes for allergen immunotherapy. Hum Vaccin Immunother. 2012;8(10): $1525-1533$.

89. Larenas-Linnemann D, Wahn U, Kopp M. Use of omalizumab to improve desensitisation safety in allergen immunotherapy. J Allergy Clin Immunol. 2014;133(3):937.e2.

90. European Aeroallergen Network [webpage on the Internet]. Polleninfo. org. Available from: https:/www.polleninfo.org/GB/en/current-data html?poll=6\&month=9\&tabber=6\&time=1. Accessed May 1, 2016.

91. Lockey RF, Ledford DK. Allergens and Allergen Immunotherapy: Subcutaneous, Sublingual and Oral. 5th ed. Boca Raton, FL: CRC Press, Taylor \& Francis Group; 2014.

92. Kim H, Waserman S, Hébert J, et al. Efficacy and safety of ragweed sublingual immunotherapy in Canadian patients with allergic rhinoconjunctivitis. Allergy Asthma Clin Immunol. 2014;10(1):55.

93. Creticos PS, Maloney J, Bernstein DI, et al. Randomized controlled trial of a ragweed allergy immunotherapy tablet in North American and European adults. J Allergy Clin Immunol. 2013;131(5):1342. e6-1349.e6.

94. Nolte H, Hébert J, Berman G, et al. Randomized controlled trial of ragweed allergy immunotherapy tablet efficacy and safety in North American adults. Ann Allergy Asthma Immunol. 2013;110(6):450. e4-456.e4.
Patient Preference and Adherence

\section{Publish your work in this journal}

Patient Preference and Adherence is an international, peer-reviewed, open access journal that focuses on the growing importance of patient preference and adherence throughout the therapeutic continuum. Patient satisfaction, acceptability, quality of life, compliance, persistence and their role in developing new therapeutic modalities and compounds to optimize

\section{Dovepress}

clinical outcomes for existing disease states are major areas of interest for the journal. This journal has been accepted for indexing on PubMed Central. The manuscript management system is completely online and includes a very quick and fair peer-review system, which is all easy to use. Visit http://www. dovepress.com/testimonials.php to read real quotes from published authors. 